\title{
Clustering of services amid a growth in green consumption and digital technology use
}

\author{
$N V$ Vasilenko $^{1, *}, A J$ Linkov $^{2}$, and $O V$ Tokareva $^{3}$ \\ ${ }^{1}$ Department of Economics, St. Petersburg Mining University, 2 21st Line VO, St. Petersburg, Russian Federation \\ ${ }^{2}$ Department of Economics and Economic Education, Russian State Herzen Pedagogical University, 48 Emb. of the Moika River, St. \\ Petersburg, Russian Federation \\ ${ }^{3}$ Department of Foreign Languages, St. Petersburg Mining University, 2 21st Line VO, St. Petersburg, Russian Federation
}

\begin{abstract}
Clustering of services in the conditions of digital economy development is considered as a way of their integration with the purpose of increasing customer satisfaction, as well as that of strengthening the competitive position of service organizations based on the promotion of green consumption. Services are clustered with the aim of satisfying one main or several interconnected needs of individuals or businesses taking into account the degree with which the consumer influences the process of service delivery. This paper demonstrates how clustering of services can be used to solve sustainability problems. It is shown that digital technologies allow the service provider to customize a service to fit the needs and requirements of a particular consumer within the first type of clustering in the service sector, and they are also included in the service support of the main service within the second type of clustering. Moreover, these technologies have their own value for the consumer within the third type of clustering and provide tools for the fourth type of clustering. In general, digitalization promotes technologization and cooperation in service clusters. The authors suppose that further research can be done into how the types of clustering mentioned manifest themselves in different industries.
\end{abstract}

\section{Introduction}

In the modern world, the tertiary sector of the economy, which is also known as the service sector, is growing. This sector covers different types of economic activity which can transcend the boundaries of a given industry $[1,2]$ and serves as a mediator as well as a support provider [3, 4]. It also aims to meet the needs of individuals. The tertiary sector plays an important role in solving sustainability problems and promoting green consumption.

Due to the expansion of the service sector, new types of services and more complex forms of servicing are emerging. The strengthening of non-price methods of competition motivates service organizations to diversify their activities, which in turn intensifies service integration. As a result, different types of services provided to individuals (for example, leisure or food services) or companies (for example, business or industrial services) become interconnected. From the spatial point of view, such integration manifests itself in the process of clustering, which is understood as a special approach to choosing locations for providing services [5].

The search for optimal combinations of services provided in one place either on site or online is necessary and beneficial for the service provider because it can help to improve the development strategy of the service organization as well as its financial performance and also to make it more competitive. As for consumers, this search can help them to satisfy their needs more fully, especially if there are particular budget constraints.

In the digital economy, conditions are created that make it possible to reduce cooperation and transaction costs. This facilitates cooperation between service organizations and fosters clustering [6]. It is important to note that the subject of the current research is the clustering of services as products rather than the clustering of service organizations.

From an organizational and economic point of view, however, the provision of services significantly differs from that of material goods. Currently, the characteristics of service activities are mainly studied within such branches as services marketing [7] and service quality management $[8,9]$. This can be explained by the fact that the differentiation of services offered by the market makes it necessary to promote sales. These branches also study ecosystem services $[10,11]$ and ways of improving the quality of services promoting green consumption.

\section{Materials and methods}

The original meaning of the term 'cluster' focuses on the locational attribute of the cluster as a structure that incorporates groups located near each other which

\footnotetext{
* Corresponding author: nvasilenko@mail.ru
} 
cooperate in certain areas while competing in others $[12$, 13]. In later works, the locational attribute was supplemented by a cooperational one, which manifests itself as a special institutional environment that creates a balance between cooperation and competition, and a technological one, which is understood as a nonlinear innovation process $[14,15]$. As a rule, the cluster incorporates companies of different types and sizes which are interested in mutually beneficial cooperation and development [16]. Companies within the cluster acquire competitive advantages through network effects and the division of labor $[17,18]$.

Clustering in the service sector is a form of spatial integration which is gaining momentum as more and more services are becoming digitized. The aim of the research is to identify the main areas of cluster formation in the service sector using services connected with sustainable customer behavior as an example and to study the role of digital technologies in the clustering process.

\section{Results}

Taking into account the fact that the consumer can influence the process of service delivery in different ways, as well as the fact that it is impossible for a consumer to accumulate and store services since they are intangible, services are clustered with the aim of satisfying one main or several interconnected needs of individuals. Clustering of services involves the development and delivery of service support. The type of technology used predetermines the nature of the service process, namely the delivery of a main service.

The authors distinguish between four types of clustering in the service sector:

- type based on the provision of a service product to the consumer, with one or more producers satisfying the customer's needs on site or online (the first type);

- type based on the provision of ancillary services accompanying the main service on site or online by means of one or several producers (the second type);

- type based on the provision of customer services aimed at reducing transaction costs in the process of fulfilling one or several needs and delivered by different providers in one place (the third type);

- type based on the provision of business services (the fourth type).

\section{Discussion}

\subsection{Network clusters based on the provision of a service product}

The first type of service clustering can be observed in such service organizations as fitness clubs that fulfill the needs of the customer in sports and promote a healthy lifestyle. Services clustered in this fashion promote sustainable consumer behavior among individuals and improve the quality of workforce by positively influencing their physical and mental health.
The cluster of services provided to visitors to a fitness club usually includes:

- passes to gyms and swimming pools as well as individual and group exercise classes;

- sauna services;

- cosmetology and massage services in spa centers;

- information services about new programs, discounts, etc.;

- medical services, including nutrition ones;

- parking spaces for private vehicles,

- storage services, including storage of valuables;

- retail distribution of sports products, etc. [19].

In terms of their organizational structure, such service organizations rely on franchising. As for the technological aspect, they are supported by digital technologies. The efficiency of a cluster of the first type can be improved by the use of various data processing technologies. For example, such technologies are used in smart card systems which make it possible to customize fitness club services to the needs and requirements of a particular consumer.

\subsection{Network clusters based on the provision of ancillary services accompanying main services}

The second type of service clustering can be seen on roads where drivers and travelers are provided with a wide range of services [20,21]. This type of clustering promotes the development of ecotourism on both local and global scales.

The system of services provided on roads includes such infrastructure facilities as motels, camping sites, petrol stations, car washes, car service stations, shops, cafés, etc. The most attractive roads for this type of clustering are those with tourism potential along which objects of natural, historical, and cultural heritage are concentrated.

At present, the clustering of services provided on roads is significantly influenced by automation which replaces workers with technology such as ticket or beverage dispensers, car park ticket machines, etc., as well as by mobile payment applications which are convenient to use.

\subsection{Network clusters based on the provision of customer services}

The third type of service clustering can be found in shopping centers $[22,23]$. Such centers provide a lot of entertainment options as they usually include cafes, restaurants, cinemas, gyms, water parks, aquariums, billiards halls, bowling alleys, amusement rides, and ice rinks. They also provide venues for various events, including workshops, trainings, exhibitions, concerts, etc.

At the bottom of the third type of clustering lies the desire of consumers to fulfill several needs in one place. The fact that shopping centers provide customers with food services, sanitation facilities, and amusement areas means that the amount of time spent by consumers in such clusters increases. Clusters of the third type create 
conditions for the consumption of environmentally friendly products. A very important factor which influences the efficiency of service organizations comprising such a cluster is the use of energy-saving technologies, including smart building technologies, big data, and IoT.

In addition, this type of clustering necessitates the development of long-term partnerships between shopping center owners and tenants. Interconnections within the cluster should contribute to improving the quality of services provided through joint searches for new solutions, exchange of information, analysis of market needs, and pooling of resources.

Clusters of this type are characterized by the delivery of services provided by digital technologies not only as a component of service support for other services, but also as products having their own value to consumers, for example, entertainment such as 3D or 4D films.

\subsection{Network clusters based on the provision of business services}

The fourth type of service clustering is connected with the activities of business centers and business incubators $[24,25]$. As a rule, tenants in these centers are engaged in the provision of different services, but they have similar needs in terms of supporting their business activities. Among the services and service products which tenants may need are:

-in terms of management and service: parking spaces and cleaning services, clock-in and clock-out systems, elevators, conference rooms, meeting rooms, and catering facilities;

-in terms of location and environment: transport accessibility, the exterior of the building, the prestige of the area, and the image of other tenants;

-in terms of infrastructure of the building: availability of technology and equipment necessary for the company to run its activities, availability of landlines and broadband connections;

-in terms of security: fire protection system, video surveillance and safety alarms.

In almost all of these areas, it is possible to provide high-quality services which take into account environmental standards only with the use of various digital technologies. The main issues of sustainable development which can be addressed by service organizations include:

- resource efficiency, including saving energy and water; - more efficient waste disposal, including recycling;

- creation of an ergonomic environment for the employees and customers of tenants as well as for companies that provide services to tenants in business centers and business incubators.

\section{Conclusions}

Clustering in the service sector is associated with the consumer's desire to save on interaction costs and with the specific properties of services, namely the fact that it is impossible to accumulate and store them. In response to customers' needs, services are clustered based on the provision of:

- a service product, which was shown using an example of a fitness club that provides the customer with a package of services in order to fulfill their need for keeping fit, with one or more companies satisfying the customer's needs on site or online;

- ancillary services accompanying main services, which was shown using an example of services provided on roads to passengers or travelers by one or several companies in the course of the customer's journey;

- customer services, which was shown using an example of shopping centers that help customers to reduce their costs in the process of fulfilling one or several needs using services provided by different companies in one place;

- business services, which was shown using an example of business centers that provide entrepreneurs with a range of services, including business ones.

As a result of clustering in the service sector, consumers are given an opportunity to reduce their interaction costs, service organizations get a number of benefits from clusters, and society as a whole gets an environment where sustainable consumer behavior can be fostered.

Digitalization promotes technologization and cooperation in service clusters, providing a platform for delivering services and service support and for their automation.

The authors suppose that further research can be done into how the four different types of clustering manifest themselves in different industries in order to identify ways of increasing the competitiveness of service organizations in the respective types of markets, as well as to improve state policy in this area.

\section{References}

[1] A. Benyoussef, I. Zaiem, Service orientation as a strategic marketing tool: the moderating effect of business sector, Competitiveness Review, 27, 1, 40-61 (2017).

[2] J. Na, J-D. Lee, C. Baek, Is the service sector different in size heterogeneity?, J. of Economic Interaction and Coordination, 12, 1, 95-120 (2017).

[3] S.V. Ignatieva, O.A. Kroll, Motor transport flows in megalopolises: a logistic and organizational assessment of regulation, J. of Mining Institute, 201, 162-168 (2013).

[4] E.A. Krainova, A.V. Kuznetsov, Evaluation of the competitiveness potential of the Russian market of geophysical services, J. of Mining Institute, 201, 185-190 (2013).

[5] L. Rivera, Y. Sheffi, D. Knoppen, Logistics clusters: The Impact of Further Agglomeration, Training and Firm Size on Collaboration and Value Added Services Int., J. of Prod. Econ., 179, 285-294 (2016).

[6] D. Pickernell, P.A. Rowe, M.J. Christie, D. Brooksbank, Developing a Framework for 
Network and Cluster Identification for Use in Economic Development Policy-Making, Entrepreneurship and Reg. Develop., 19, 339-358 (2007).

[7] Ch. Lovelock, J.J. Wirtz, Services Marketing: People, Technology, Strategy, USA: World Scientific Publishing Co. Inc., 776 (2016).

[8] C.A. Gronroos, Service quality model and its marketing implications European, J. of Marketing, 18, 4, 36-44 (1991).

[9] V.A. Zeithaml, A. Parasuraman, L.L. Berry, Problems and Strategies in Services Marketing, J. of Marketing, 49, 33-46 (1985).

[10] A.G. Rosenberg, Ecosystem services of the districts of the Samara region, Bulletin of the Samara State University of Economics, 7 (129), 55-59 (2015).

[11] R. Costanza, H.E. Daly, Natural Capital and Sustainable Development, Conservation Biology, 16, 37-46 (1992).

[12] M. Porter, Competition, Moscow: Viljams, 608 (2005).

[13] J. Swords, M. Porter's, Cluster Theory as a Local and Regional Development Tool: The Rise and Fall of Cluster Policy in the UK Local Econ, 28, 369-383 (2013).

[14] S. Korobov, V. Mosejko, S. Fomina, Use of Cluster Concept in the Development of Regional Entrepreneurship, Busin. Educ. Right, 2, 108-114 (2014).

[15] N. Lisovskaya, Cluster Approach to the Regional Economics Development, Busin. Educ. Right, 3, 135-139 (2012).

[16] H. Wolman, D. Hincapie, Clusters and ClusterBased Development Policy Econ, Develop. Quarterly, 29, 135-149 (2015).

[17] C. Ketels, Recent Research on Competitiveness and Clusters: What are the Implications for Regional Policy?, Cambr. J. of Regions, Econ. and Soc., 6, 269-284 (2013).

[18] V. Navickas, A. Malakauskaite, The Impact of Clusterization on the Development of Small and Medium-Sized Enterprise (SMA) Sector, J. of Busin. Econ and Manag, 10, 255-259 (2009).

[19] S.A. Vinogradova, N.V. Sorokina, T.S. Zhdanova, Organization and planning of the enterprise service activities, Moscow: Dashkov and K, 208 (2014).

[20] T. Bessonova, I. Kuzmenkova, Roadside Service of Belarus: Normative Base, Problems and Development Prospects Consumer Coop., 1, 1620 (2015).

[21] L. Tracevskaya, Roadside Service in Belarus: National and Regional Aspect Law, Econ. Psychol, 1, 37-44 (2015).

[22] F. Abdrazakov, A. Pomorova, N. Medvedeva, Organizing Rental Relations of Shopping (Shopping and Leisure), Centers Real Estate: Econ., Manag, 1, 20-23 (2017).

[23] V. Il'in, V. Choj, Shopping and Entertainment Center as Space Making Quality of Life In
Russia, Sociologicheskie issledovaniya, 4, 82-92, (2017).

[24] G. Voroncova, N. Yakubova, The Modern Trends in Development of Business Incubator in Stavropol, Region Newsletter of North-Caucasus Fed Un, 4, 80-84 (2017).

[25] N. Korolkov, Evaluation of the Quality of Service Business Centers Property, Relations in the Rus Fed, 5, 66-87 (2013). 